\title{
TIAGO ESTEVAM DE ALMEIDA
}

\section{INSULINA SEMELHANTE A FATOR DE CRESCIMENTO NA REPARAÇÃO ÓSSEA}

\author{
São Paulo
}




\title{
TIAGO ESTEVAM DE ALMEIDA
}

\section{INSULINA SEMELHANTE A FATOR DE CRESCIMENTO NA REPARAÇÃO ÓSSEA}

\author{
Dissertação apresentada à Faculdade de \\ Odontologia da Universidade de São Paulo \\ para obter o título de Mestre, pelo \\ Programa de Pós-Graduação em \\ Odontologia. \\ Área de Concentração: Cirurgia Oral e \\ Traumatologia Maxilo Facial. \\ Orientador: Prof. Dr. Antonio Silvio Fontão \\ Procópio
}

São Paulo

2004 


\section{FOLHA DE APROVAÇÃO}

Almeida TE. Insulina Semelhante a Fator de Crescimento na Reparação Óssea. [Dissertação de Mestrado]. São Paulo: Faculdade de Odontologia da USP; 2004.

São Paulo, 25/10/2004

\section{Banca Examinadora}

1)Prof(a). $\operatorname{Dr}(a)$.

Titulação:

Julgamento:

Assinatura:

2) $\operatorname{Prof}(a) . \operatorname{Dr}(a)$.

Titulação:

Julgamento:

Assinatura:

3)Prof(a). Dr(a).

Titulação:

Julgamento:

Assinatura: 


\section{DEDICATÓRIA}

Aos meus familiares que com amor, compreensão e carinho me apoiaram ao longo do período de elaboração deste trabalho.

Aos meus amigos do Movimento de Emaús, em especial aos Padres Sanclei e Marcelo, que sempre me motivaram a multiplicar os meus talentos.

Aos Professores da Disciplina de Cirurgia Bucal e Traumatologia Maxilo Facial, pricipalmemte meu Orientador Prof. Dr. Antonio Silvio Fontão Procópio, que me serviram de modelo profissional. 
Almeida TE. Insulina Semelhante a Fator de Crescimento na Reparação Óssea [Dissertação de Mestrado]. São Paulo: Faculdade de Odontologia da USP; 2004.

\section{RESUMO}

Em nossos dias, a Cirurgia e Traumatologia Buco-Maxilo-Facial busca novas terapêuticas tendo como meta uma rápida reparação, osteointegração e regeneração dos tecidos ósseos e periodontais. Uma diminuição do tempo de reparação em fraturas e cirurgias ortognáticas, uma reparação normal de defeitos ósseos de tamanho crítico sem a utilização de enxertos e a redução do tempo de osteointegração de implantes possibilitará redução da morbidade, dos custos e uma reabilitação protética com menor período de tempo. Uma alternativa recente

é a utilização de Fatores de Crescimento Semelhante a Insulina (IGFs) para a estimulação da proliferação e reparação tecidual.

Os resultados observados na revisão de literatura indicam que as futuras terapias com IGFs propiciarão um avanço em relação à velocidade de reparação óssea, reparação em defeitos ósseos de tamanho crítico e em implantes imediatos.

Palavras-Chave: IGF-I; IGF-II; Reparação de Feridas 
Almeida TE. Insulin Like Growth Factor in Bone Repair [Dissertação de Mestrado]. São Paulo: Faculdade de Odontologia da USP; 2004.

\begin{abstract}
In our days, the Oral and Maxillofacial Surgery search new techniques to goal a quick repair, osteointeration and regeneration of bone and periodontal tissues. A diminution of time healing of bone fractures and ortognatic surgery, a normal healing in critics bone defects without grafts and a decrease time of osteointegration will make possible a low morbidity and a rapid protetic rehabilitation. An newly alternative is the use of Insulin Like Growth Factor (IGFs) to estimulate the tissue proliferation and healing.

The results discovered in literature review indicate that future therapies with IGFs provide an advance in speed of bone healing, healing critical bone defects and immediate implants.
\end{abstract}

Keywords : IGF-I; IGF-II; Wound Healing 


\section{LISTA DE ABREVIATURAS E SIGLAS}

IGF Insulina Semelhante a Fator de Crescimento

IGF-I Insulina Semelhante a Fator de Crescimento I

IGF-II Insulina Semelhante a Fator de Crescimento II

IGFBP Proteínas Ligantes de IGF

BMP Proteína Morfogenica Óssea

GH Hormônio de Crescimento

$\mathrm{SO}_{4}$ Sulfato

TGF- $\beta$ Fator de Crescimento Transformante $\beta$

NSILA Insulina com Atividade Não Suprimível

MAS Estimulante da Atividade Multiplicadora

PTH Hormônio Paratiroidiano

T3 Tiiodo tironina

PDGF Fator de Crescimento Derivado de Plaquetas

$\mathrm{PGE}_{2}$ Prostaglandina $\mathrm{E}_{2}$

PTFE polytetrafluoroethyleno

VGEF Fator de Crescimento Vascular Endotelial

Células Ob Tipo de Cultura Osteoblástica

$1,25-(\mathrm{OH})_{2} \mathrm{D}_{3} \quad 1,25$-Dihydroxyvitamina $\mathrm{D}_{3}$

PDLLA Poly (D, L Lactid) ou Lactosorb

FGF Fator de Crescimento Fibroblástico

DNA Ácido Desoxiribonucleico 
RNAm Ácido Ribonucléico mensageiro 


\section{SUMÁRIO}

1 INTRODUÇÃO

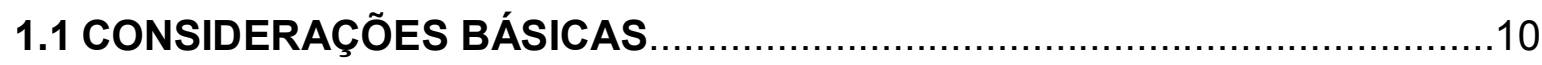

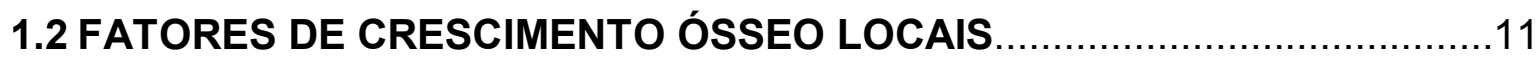

1.3INSULINA SEMELHANTEA FATOR DE CRESCIMENTO ...........................12

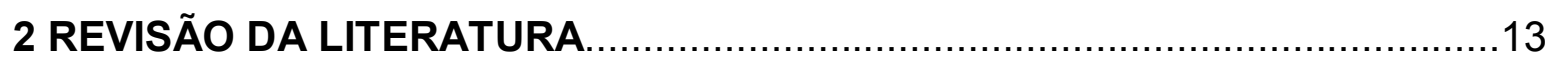



2.2 PAPEL DAS IGFS NO CRESCIMENTO ESQUELÉTICO_...........................18

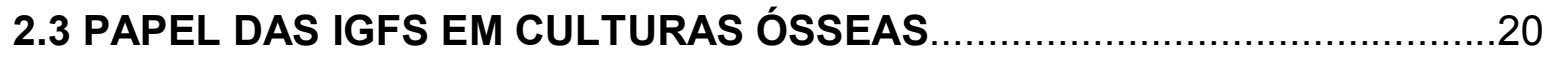

2.4 O PAPEL DAS IGFS NO REPARO E CRESCIMENTO EM ÓSSOS

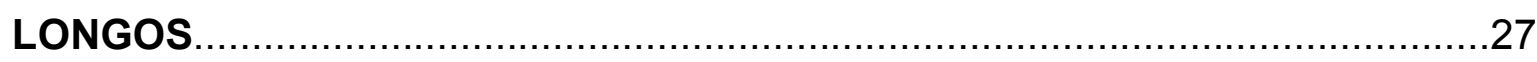

2.5 O PAPEL DAS IGFS NO REPARO E CRESCIMENTO EM OSSOS DE ORIGEM INTRA MEMBRANOSA

3 PROPOSIÇÃO

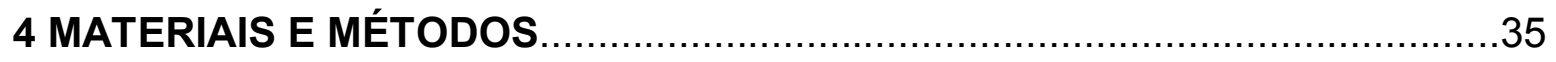

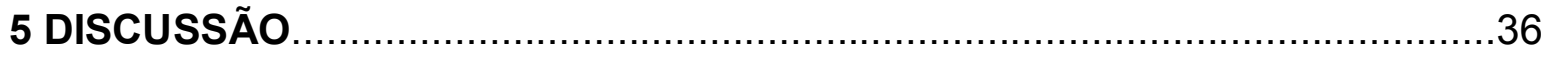

5.1 PAPEL DAS IGFS NO CRESCIMENTO ESQUELÉTICO............................38

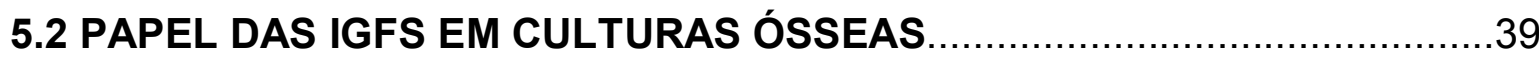


5.3 O PAPEL DAS IGFS NO REPARO E CRESCIMENTO EM ÓSSOS

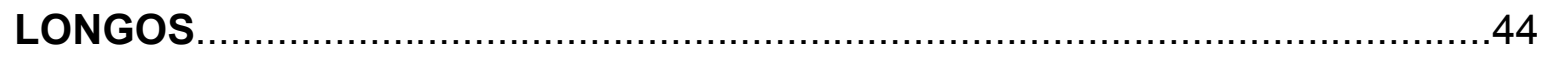

5.4 O PAPEL DAS IGFS NO REPARO E CRESCIMENTO EM OSSOS DE

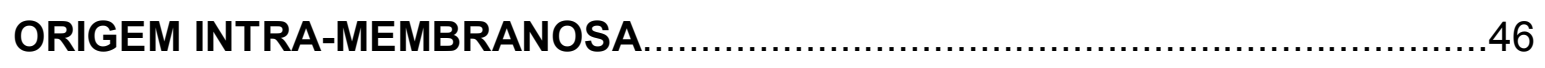

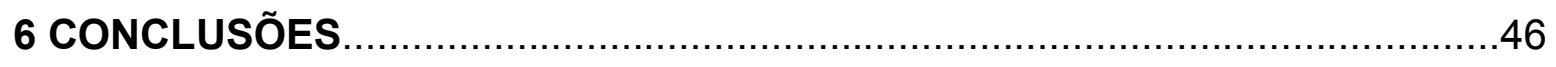

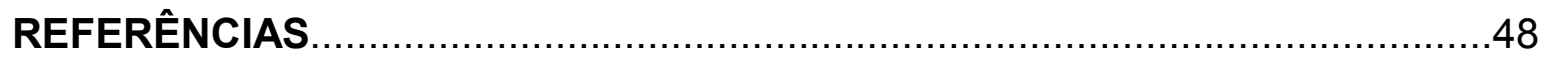




\section{INTRODUÇÃO}

Em nossos dias, a Cirurgia e a Traumatologia Buco-Maxilo-Facial buscam novas terapêuticas tendo como meta uma rápida reparação, osteointegração e regeneração dos tecidos ósseos. Uma diminuição do tempo de reparação no tratamento de fraturas e cirurgias ortognáticas, uma reparação normal de defeitos ósseos de tamanho crítico sem a utilização de enxertos, uma redução do tempo de osteointegração de implantes possibilitarão redução da morbidade, dos custos e uma reabilitação protética com menor período de tempo.

Uma alternativa recentemente sugerida pela literatura é a utilização de fatores de crescimento. Estes fatores individualmente ou em associações poderão em um futuro próximo melhorar sensivelmente a reparação óssea e tecidual nas diversas especialidades odontológicas e médicas.

O termo fator de crescimento é aplicado a um grupo de polipeptídeos que estão envolvidos na proliferação celular, diferenciação e morfogênese dos tecidos e orgãos durante a embriogenese e no crescimento pós-natal. Fatores de crescimento podem atuar como mitogênicos que incrementam a proliferação de certos tipos de células. Alguns fatores de crescimento também são morfogênicos mudando o fenótipo das células alvo. Também atuam de forma autócrina, parácrina ou até endocrina, pois apresentam altos níveis séricos (SCHLIEPHAKE, 2002). 
Dentre todos os fatores crescimento nós escolhemos a família dos Fatores de Crescimento Semelhante a Insulina (IGFs), para que através da revisão de literatura estudássemos o seu papel na estimulação e reparação óssea visando desenvolver trabalhos de pesquisas futuros.

\subsection{CONSIDERAÇÕES BÁSICAS}

A formação de osso novo, ou seu modelamento ocorre durante o desenvolvimento fetal e neonatal, onde o total da massa de tecido esquelético aumenta. Também, a formação óssea durante a remodelação ocorre para continuar o crescimento, para maturação óssea ou para contrapor a reabsorção óssea necessária para a manutenção sérica dos níveis de cálcio.

Todos os tipos de formação óssea são conhecidos por depender de fatores de crescimento que são expressos dentro, próximo ou chegando ao tecido esquelético, atuando na regulação da proliferação celular, diferenciação, síntese

de matriz e deposição mineral. A remodelação óssea também é influenciada por fatores sistêmicos que causam mudanças na liberação local de fatores de crescimento. As fases iniciais do reparo ósseo de fraturas também seguem estas mesmas regras em relação aos fatores de crescimento, embora seja muito influenciada através dos fatores relacionados à inflamação (MACCARTHY; CHANGHUA; CENTRELLA, 2000). 
No crescimento ou no reparo ósseo, células progenitoras de células ósseas, os osteoblastos, necessitam se proliferar para reabastecer as células perdidas. Um grande número de fatores de crescimento locais tem potencial de aumentar a replicação celular óssea. Muitos fatores de crescimento locais atuam em células alvo como as células precursoras de osteoblastos, enquanto outras atuam nos osteoblastos diferenciados e outros fatores dirigindo o processo de diferenciação.

Uma regra essencial para osteoblastos diferenciados é a produção de nova matriz osteóide, composta primariamente de colágeno tipo I, de diversas outras macromoléculas e proteínas ligantes minerais. Também os osteoblastos têm um papel importante no desenvolvimento e ativação osteoclástica, a qual ocorre em parte através da expressão de citokinas ou co-ativadores e fatores de crescimento que afetam a diferenciação osteoclástica ou suas precursoras. A sinalização inicial que dirige a proliferação, diferenciação, e função celular da linhagem osteoblástica é controlada por um pequeno número de fatores de crescimento, com particular foco para a formação de osso novo (MACCARTHY; CHANGHUA; CENTRELLA, 2000).

\subsection{FATORES DE CRESCIMENTO ÓSSEO LOCAIS}


Nos últimos 17 anos, muitos fatores de crescimento foram identificados no tecido ósseo e mostraram in vitro e in vivo a capacidade de ativar a replicação celular e ativação do tecido ósseo.

Na sua grande maioria, os fatores de crescimento produzidos pelas células ósseas ou os encontrados em associação com a matriz óssea, estão em níveis altos que excedem as quantidades necessárias para uma estimulação máxima celular. Entretanto, alguns fatores de crescimento são liberados em combinação com proteínas ligantes que mantêm estes em estado inativo, protegendo-os da degradação (LINKHART; MOHAN; BAYLINK,1996).

Os fatores de crescimento podem ser classificados como ativadores ou supressores da replicação osteoblástica e como diferenciadores, por promoverem a deposição de matriz ou produzir a mineralização (MACCARTHY; CHANGHUA; CENTRELLA, 2000).

Muitos fatores de crescimento apresentam mais de uma função, podendo ativar ou suprimir um ou mais processos, sendo que a resposta celular está relacionada com a quantidade de fatores de crescimento liberados, tempo de exposição e diferenças no modo de ativação celular (SCHLIEPHAKE, 2002).

Com relação ao reparo ósseo, muitos fatores de crescimento são conhecidos por ativar osteoblastos maduros ou seus precursores, mas alguns têm papel mais proeminente no desenvolvimento ósseo, seu remodelamento e reparo. Destes, as três principais famílias são IGFs, TGF- $\beta$ s e BMPs, que aparecem em vários aspectos da atividade óssea, ou mediam, induzem ou modulam os efeitos de outros reguladores do crescimento ósseo. Cada um destes fatores de crescimento pode controlar as replicações específicas das subpopulações de 
células ósseas, bem como a expressão de células associadas, como por exemplo o endotélio e por fim a secreção das moléculas necessárias para síntese de matriz ou deposição mineral (MACCARTHY; CHANGHUA; CENTRELLA, 2000).

\subsection{INSULINA SEMELHANTE A FATOR DE CRESCIMENTO}

A IGF-I é um polipeptídeo com 70 aminoácidos e com $49 \%$ de homologia com a estrutura da insulina. Já a IGF-II apresenta 67 amioácidos com uma homologia de $61 \%$ (SCHLIEPHAKE, 2002).

A ação deste fator de crescimento foi descrita pela primeira em 1957, seguida por outros trabalhos que descreveram a estrutura e as ações deste fator de crescimento (SALMON; DAUGHADAY, 1957).

O objetivo deste trabalho de dissertação é discutir os principais aspectos de ação das IGFs na reparação óssea. 


\section{REVISÃO DE LITERATURA}

\subsection{HISTÓRICO}

Em 1957, Salmon e Daughaday (1957) observaram que o soro estimulava a incorporação de ${ }^{35} \mathrm{SO}_{4}$ (sulfato com marcador radioativo) em incubações de cartilagem. Neste mesmo trabalho observaram que o soro de ratos hipofisectomizados foi destituído de sua ação de sulfatação. Este fenômeno poderia ser corrigido com a adição de Hormônio de Crescimento (GH) em ratos, mas não em meios de cultura. Isto levou aos autores a postular que o $\mathrm{GH}$ não estimulava sozinho o processo de crescimento in vitro ou in vivo, mas dependia de outros fatores. Estes fatores foram chamados primeiramente de sulfactantes e depois de somatomedinas.

Froesch et al. (1963) observaram que o soro exercia efeitos semelhantes a insulina nos tecidos alvo como músculos e tecidos adiposos. Este efeito era muito maior do que se esperaria com base na insulina encontrada no soro. Além disso, os efeitos semelhantes à insulina do soro não eram suprimidos pela adição de um soro anti-insulina. Estas moléculas responsáveis por este efeito foram chamadas de NSILA.

Daughaday et al. (1972) afirmaram que "não há mais dúvidas na importância no crescimento e resposta anabólica de tecidos esqueléticos do fator de sulfactação, embora o mecanismo de produção e o principal papel fisiológico deste fator ainda estejam indefinidos". 
Pierson e Temin (1972) extraíram fatores do soro que chamaram de fatores estimuladores da atividade de estimulação. Estes fatores quando adicionados a meios de cultura estimulavam a replicação celular.

Dulak e Temin (1973) encontraram em culturas de células hepáticas a secreção dos fatores estimuladores.

Zapf, Waldvogel e Froesch (1975) concluíram que as IGFs não existem em sua forma livre no soro ou em outros fluídos corpóreos.

Rinderknecht e Humbel (1978) purificaram e caracterizaram as moléculas responsáveis por esta atividade semelhante a insulina. A estrutura da IGF-I consiste de 70 resíduos de aminoácidos e a da IGF-II de 67 resíduos de aminoácidos. Os Fatores de Crescimento Semelhante a Insulina (IGFs) não eram só funcionalmente, mas também estruturalmente semelhantes a insulina.

Herington e Kuffer (1981) observaram que frações do plasma humano contêm quantidades significantes de proteínas supressoras de NSILA. Os autores concluíram que a ação da NSILA não é só mediada por sua forma livre ou suas proteínas ligantes, mas também pela quantidade destes inibidores específicos.

Schwander et al. (1983) concluíram que as IGFs são continuamente sintetizada e armazenadas pelo fígado, assumindo meia vida de 3 horas em ratos normais. Além disso, sugeriram que o fígado é o maior sítio de produção de IGFs em ratos. Por fim observaram que o fígado também é fonte de proteínas ligantes de IGF (IGFBPs) e que as IGFs e as IGFBPs são secretadas independentemente.

Mayer e Schalch (1983) concluíram que as IGFs poderiam ser produzidas por células de outros tecidos em menor quantidade. 
Os grandes fatores regulatórios da concentração de IGF no soro são os níveis de $\mathrm{GH}$, a nutrição, a secreção adequada de insulina e provavelmente também a função tiroidiana, sem a qual a secreção de GH é diminuída, concluíram Froesch et al. (1985) em revisão de literatura. Os autores também relataram que as IGFs em sua forma ligada com as IGFBPs não exercem reação cruzada com os efeitos da insulina. E, por fim, afirmaram que as IGFs também exercem efeitos nos tecidos alvo da insulina, como o aumento do metabolismo da glicose no tecido adiposo.

Rechler e Nillley (1985) concluíram que o receptor tipo I é composto por subunidades $\alpha$ e $\beta$ ligadas dissulfidricamente. A subunidade $\alpha$ liga-se a hormônios. Já a subunidade $\beta$ parece ter uma atividade intrínseca de tirosina Kinase e se autofosforila. Os receptores tipo I preferencialmente ligam-se a IGF-I, mas também ligam-se a IGF-II e mais raramente à insulina. Os receptores tipo II contêm uma ponte dissulfídrica interna, mas não ligada a outros componentes de membrana. Os receptores tipo II ligam-se com grande afinidade à IGF-II comparando com a IGF-I, não interagindo com a insulina em grandes concentrações. Já os receptores de IGF tipo I e os receptores de insulina são homólogos estruturalmente. Ambos ligam-se a IGFs e insulina.

Zapf et al. (1986) concluíram que somente as IGFs em sua forma livre, e não as IGFs com as proteínas ligantes (IGFBPs), são biologicamente viáveis na ação nos tecidos alvo.

Murphy et al. (1987) estudaram o DNA-C da IGF-I para provar a abundância do RNAm da IGF-I em tecidos de ratos adultos e demonstrar a dependência da 
expressão de IGF-I pelo GH em vários tecidos. Os autores concluíram que a transcrição de IGF-I ocorre no fígado e em muitos tecidos, o que apoia fortemente a ação autócrina do IGF-I. Embora os níveis de expressão de IGF-I nos tecidos sejam baixos demonstraram muitos graus de dependência do $\mathrm{GH}$.

Holly e Wass (1989) concluíram que as IGFs têm ação autócrina e parácrina em muitos tecidos, e também mediam as ações do $\mathrm{GH}$.

Bautista, Mohan e Baylink (1990) estudaram se a IGF-I e II humanas estavam conservadas no tecido esquelético de uma variedade espécie de vertebrados. Os autores concluíram que a IGF-I estava presente em todos os animais estudados, sendo que a IGF-I apresentava-se em maiores quantidades nos macacos, cachorros e ratos adultos quando comparados com humanos. Comparando os níveis relativos, houve em geral mais IGF-II que IGF-I. Por fim, com relação à concentração destes 2 polipeptídeos no tecido esquelético a maior concentração foi encontradas em humanos e em cachorros.

Linkhart, Mohan e Baylink (1996) realizaram revisão de literatura a respeito do papel dos fatores de crecimento na reparação e crescimento ósseo. As conclusões à respeito das IGFs foram que a IGF-I e IGF-II estimulam a proliferação celular óssea e funções variadas como a expressão do colágeno tipo 1. A expressão de IGFs é relativamente alta em células de desenvolvimento ósseo e periostal, reparo de fraturas e desenvolvimento ósseo induzido por matriz de osso desmineralizada. Em ratos, as IGFs aumentam a formação de precursores de osteoblastos. As IGF-I e IGF-II são os fatores de crescimento mais abundantes armazenados na matriz óssea. Por ter meia vida curta, as IGFs necessitam de 
proteínas ligantes IGFBPs. Existem 6 tipos de IGFBPs, sendo que as IGFBP 3 e 5 podem potencializar a atividade das IGFs em osteoblastos.

Bianda et al. (1997) concluíram que a IGF-I estimula rapidamente a remodelação óssea e parece mediar os efeitos renais do $\mathrm{GH}$ na produção de 1,25 $(\mathrm{OH})_{2} \mathrm{D}_{3}$ independentemente do PTH em jovens adultos.

MacCarthy, Changhua e Centrella (2000), em trabalho de revisão de literatura, concluíram que agentes como o $\mathrm{PTH}$ e a $\mathrm{PGE}_{2}$ rapidamente induzem a expressão de IGF-I em osteoblastos. Assim, os autores propuseram que a IGF-I poderia atuar como um fator de união para a remodelação óssea.

Butler e LeRoith (2001) realizaram revisão de literatura, na qual concluíram que, "de todos os fatores de crescimento estudados, um que trará benefícios em novas técnicos de terapias gênicas são as IGFs propiciando ao longo do tempo um controle de sua expressão". Estudos confirmam que o desenvolvimento da maioria, se não de todos tecidos e órgãos são regulados em algum grau pelo sistema IGF. A família dos ligantes e receptores de IGF é homóloga à combinação de insulina/receptores de insulina sugerindo uma comum evolução hereditária.

Schilephake (2002) concluiu que as IGFs são cadeias únicas de peptídeos que existem em 2 formas: IGF-I 97 (aminoácidos) e IGF-II (67 aminoácidos). As IGFs têm entre $40-50 \%$ de homologia entre com a insulina. Apesar desta homologia cada uma tem receptores únicos. A IGF-I tem sido considerada um mediador circulante do GH. Seis proteínas ligantes (IGFBPs) das IGFs foram identificadas. Estas proteínas facilitam o transporte das IGFs e regulam sua função celular. De todas as IGFBPs, a IGFBP5 é abundante dentro da matriz óssea e, existe uma hipótese que a função da IGFBP 5 é incorporar as IGFs 
dentro da matriz óssea mineralizada. Em culturas de osteoblastos, a IGF-I tem efeito quimiotático em osteoblastos. Já a IGF-II tem a mesma ação com uma potência menor. Também a contração do colágeno lactide foi aumentado in vitro e isto serve como indicador do reparo de feridas. In vivo a aplicação de IGF-I sistemicamente ativou rapidamente o turn over ósseo com aumento no soro de osteocalcina e carboxyterminal propeptídeo do colágeno 1, concluiu o autor.

\subsection{PAPEL DAS IGFS NO CRESCIMENTO ESQUELÉTICO}

Schoenle et al. (1982) concluíram que a IGF-I administrada em ratos hipofisectomizados mimetiza os efeitos do $\mathrm{GH}$ sobre o crescimento de ossos longos e ganho de peso.

Analisando os efeitos da administração sistêmica de GH e IGF-I no crescimento longituninal de ossos longos de ratos, Isagaard et al. (1986) confirmaram e ampliaram as investigações anteriores, mostrando que a administração local de IGF-I estimulou o crescimento longitudinal ósseo.

Mathews et al. (1988) demonstraram em ratos que a IGF-I é diretamente envolvida na mediação do sinal do GH e que a falta da expressão gênica de IGF-I é responsável, pelo menos em parte, pela falta do início de outros eventos mediados pelo $\mathrm{GH}$.

DeChiara, Efstrstiadis e Robertson (1990) demonstraram uma relação causal entre a eliminação da função de um alelo da IGF-II e a deficiência 
fenotípicas de crescimento que inicia aparentemente no início embrionário com 16 dias e persiste após o nascimento. Apesar do pequeno tamanho (60\% do peso normal), os ratos heterozigóticos parecem normais e alcançam a maturidade sexual. Ambos, machos e fêmeas, heterozigóticos eram férteis e transmitiam a mutação depois de cruzarem com animais normais dando uma prole normal.

Powell-Braxton et al. (1993) observaram que ratos com falta de um gene funcional de IGF-I obtiveram progresso em seu crescimento pré-natal e nasceram. Mas seu tamanho era muito menor que o de ratos normais. Eles tinham severa distrofia muscular e a maioria destes ratos morreu ao nascimento. Assim, os autores concluíram que nos ratos os níveis séricos de IGF-II são altos no feto e declinam rapidamente depois do nascimento. Em contraste, concentrações séricas de IGF-I são baixas no feto e no período pós-natal crescendo muito a partir da puberdade. Os autores sugerem a hipótese que a IGF-II funciona predominantemente no crescimento fetal enquanto a IGF-I no pós-natal.

Liu et al. (1993) concluíram que ratos homozigóticos para genes interrompidos de IGF-I exibiram deficiência similar à as encontradas em ratos com genes de IGF-II nulos (60\% do peso normal). Dependendo da bagagem genética, alguns ratos anões morreram após o nascimento, enquanto outros sobreviveram e chegaram até a fase adulta. Em contraste, ratos com genes para IGF-I nulos, morreram após o nascimento por falência respiratória.

Baker et al. (1993) também analisaram o desenvolvimento do crescimento de embriões de ratos carregando uma mutação nula de genes de IGF-I, IGF-II e receptor tipo 1 para IGF sozinhos ou em combinação. As conclusões obtidas indicam que mutantes IGF-I sobreviveram, mas eram estéreis e exibiam falta de 
desenvolvimento ósseo com níveis de crescimento retardados após o nascimento em comparação com ratos normais, chegando a $30 \%$ do peso de ratos normais.

Bikle et al. (1994) realizaram um trabalho com ratos para determinar a capacidade de produção e resposta de IGF-I, IGF-II e seus receptores durante o desenvolvimento esquelético. Para isso, mediram-se os níveis de RNAm ósseo e concluiu-se que os níveis de RNAm permaneceram altos durante o desenvolvimento fetal, mas caíram após o nascimento. Esta queda foi pronunciada para IGF-II e seus receptores. Entretanto, após 6 semanas, os níveis de IGF-I e seu receptor voltaram aos níveis do nascimento. Os autores concluíram que, durante o desenvolvimento, ocorreu uma predominância da participação da IGF-I.

\subsection{PAPEL DAS IGFS EM CULTURAS ÓSSEAS}

Canalis (1980) estudando em cultura de calvária de ratos demonstrou que a IGF-I estimula a síntese de DNA e de colágeno, indicando que a IGF-I é importante na regulação do crescimento aposicional.

Hock, Centrella e Canalis (1988), demostraram que o efeito estimulatório da IGF-I na síntese de matriz óssea em culturas de calvária de ratos parece ser conseqüência de pelo menos 2 sinais regulatórios: o primeiro é um efeito na diferenciação de osteoblastos (incremento na produção de colágeno ósseo), 
enquanto o segundo é um aumento na replicação de células osteoprogenitoras, resultando em um grande número de osteoblastos funcionais. Embora esses 2 sinais trabalhem juntos no aumento da produção de matriz eles são bioquimicamente dissociados e não são os únicos. Além disso, IGF-I afeta ambas células osteoprogenitoras e osteoblastos diferenciados, mas regula cada população celular por mecanismos independentes.

Canalis, MacCarthy e Centrella (1988) realizaram trabalho com o objetivo isolar e caracterizar as IGFs secretadas por culturas de calvária fetal de rato e estudar os possíveis papéis no controle local da formação óssea. Este estudo demonstrou que essas culturas secretam IGF-I, que estimulam o colágeno ósseo e o DNA.

Linkhart e Mohan (1989) concluíram que o PTH estimula diretamente a liberação de IGF-I e IGF-II em osteoblastos de calvária de ratos.

MacCarthy, Centrella e Canalis (1989) concluíram que as IGF-I e II estimulam a síntese de colágeno em culturas de calvária de rato e diminuem a degradação do colágeno. O efeito na síntese de colágeno não foi dependente do aumento do número de células, parecendo ser regulado em níveis de transcrição.

Canalis et al. (1989) concluíram que o efeito estimulatório do PTH na síntese do colágeno ósseo é mediado pela IGF-I. Isto pode ser comprovado já que anticorpo neutralizante de IGF-I previne o aumento da síntese óssea pelo PTH. Em resumo, o tratamento contínuo com PTH resultou em uma inibição da síntese de colágeno, enquanto o tratamento transitório estimulou a síntese de colágeno, e este efeito aparece secundariamente à produção local esquelética de IGF-I. 
Ernst, Heath e Rodan (1989) estudaram o efeito do estradiol, hormônio utilizado no tratamento da osteoporose, em culturas osteoblásticas de calvária, verificando à produção de RNAm para IGF-I. Os autores concluíram que o estradiol pode estimular diretamente a produção de colágeno e RNAm de IGF-I. Estes efeitos poderiam explicar as ações anabólicas e antianabólica do estradiol no osso.

Pfeilschifter et al. (1990) realizaram experimentos com culturas de calvária fetal de ratos, onde adicionaram IGF-I, PDGF e TGF- $\beta$. Através da utilização de auto-radiografias se mensurou a aposição de matriz óssea. Os resultados evidenciaram que a IGF-I, PDGF e TGF- $\beta$ são capazes de estimular a formação óssea in vitro.

MacCarthy, Centrella e Canalis (1990) estudaram os efeitos do cortisol na transcrição de IGF-I e nos níveis de polipeptídeos em culturas de osteoblastos e fibroblastos. Os resultados permitiram os autores concluírem que o cortisol inibe a transcrição de IGF-I e os níveis de polipeptídeos em células esqueléticas.

Centrella, MacCarthy e Canalis (1990) estudaram a potência dos receptores de IGF tipo I e tipo II para síntese de colágeno ósseo e DNA em culturas de osso parietal de ratos. As descobertas obtidas sugeriram que o efeito na síntese de colágeno ósseo e DNA ocorre através dos receptores de IGF-I.

Kurose et al. (1990) estudaram os possíveis mecanismos da interação entre a IGF-I e 1,25- $(\mathrm{OH})_{2} \mathrm{D}_{3}$ sobre os receptores de células osteoblásticas. Os autores concluíram que os efeitos da interação da IGF-I e 1,25-(OH $)_{2} D_{3}$ sobre as células osteoblásticas pode ser mediada pelo efeito da $1,25-(\mathrm{OH})_{2} \mathrm{D}_{3}$ sobre os receptores de IGF-I. 
Elford e Lamberts (1990) compararam em culturas osteoblásticas o efeito estimulatório da TGF- $\beta 1$ e do PTH na produção de IGF-I por osteoblastos. Os dados obtidos permitiram aos autores concluírem que PTH estimulou a produção de IGF-I por osteoblastos e condrócitos, enquanto a TGF- $\beta 1$ estimulou a produção de IGF-I pelos osteoblastos, mas inibiu a produção pelos condrócitos. Estes dados sugerem que o efeito da modulação de IGF-I pela TGF- $\beta 1$ tem papéis diferentes na formação óssea e cartilaginosa.

Canalis, McCarthy e Centrela (1991) estudaram os efeitos da des-IGF-I (Desamino-1-3-IGF-I) e IGF-I no DNA e síntese de colágeno e na degradação em culturas de calvária. A des-IGF-I foi mais efetiva em se ligar aos receptores de IGF tipo I enquanto a IGF-I foi mais capaz de se ligar as proteínas ligantes IGFBPs. Em síntese, a des-IGF-I incrementou a síntese de DNA e colágeno nas células osteoblásticas, algo com maior extensão que a IGF-I, apesar da menor afinidade com as IGFBPs.

Sabe-se que a $\mathrm{PGE}_{2}$ é um potente modulador da remodelação óssea influenciando tanto a reabsorção como a formação. Assim, McCarthy et al. (1991) examinaram os efeitos da $\mathrm{PGE}_{2}$ sobre os níveis de IGF-I em culturas de células ósseas $\mathrm{Ob}$ de ratos. Os autores concluíram que a $\mathrm{PGE}_{2}$ é um potente estimulador da síntese de IGF-I em culturas de células ósseas Ob.

O volume ósseo é mantido por mecanismos locais que regulam a formação e a reabsorção ósseas. Estes mecanismos são regulados por fatores de crescimento, dentre eles as IGFs. Assim Linkhart e Keffer (1991) avaliaram a liberação de IGF-I e II em culturas de calvária de ratos pelo PTH, TGF- $\beta 1$ e 1,25dihidroxivitamina $D_{3}$. O PTH e a TGF- $\beta 1$ aumentaram a liberação de IGF-I e II. Já 
o efeito 1,25-dihidroxivitamina $D_{3}$ foi similar ao efeito do PTH e da TGF- $\beta 1$ na liberação de IGF-II. Os autores concluíram que o PTH e a TGF-ß1estimularam a secreção de IGF-I e II in vitro, sugerindo importante papel na formação óssea.

Canalis, Centrela e McCarthy (1991) examinaram os efeitos dos hormônios e fatores de crescimento (cicloheximida, T3, sal sódio, TGF- $\beta 1$, bFGF, e PDGF) sobre as concentrações de IGF-II em culturas fetais de calvária de ratos com 21 dias. Os autores indicaram que os corticosteróides e bFGF promovem uma inibição na produção da IGF-II. Já a T3, o sal sódio, a TGF-ß1 e o PDGF não estimularam nem inibiram a produção esquelética da IGF-II. A inibição da expressão de IGF-II provocada pelos corticóides pode ocorrer porque este hormônio inibe a reparação óssea.

McCarthy, Centrella e Canalis (1992) objetivaram caracterizar os efeitos precoces de uma variedade de hormônios sobre a produção de IGF-II. Para isso utilizaram culturas de osteoblastos fetais de calvária de ratos. Os autores concluíram que o GH não teve efeito na expressão de IGF-II. Já o cortisol teve efeito inibitório na expressão de IGF-II.

Mochizuki et al. (1992) investigaram os efeitos da IGF-I e II sobre os osteoclastos existentes em culturas ósseas para avaliar a reabsorção óssea. A IGF-I teve efeito na estimulação da reabsorção óssea, já a IGF-II não obteve o mesmo efeito. A IGF-I também aumentou o número de osteoclástos nas áreas de reabsorção. Estes dados sugerem que a IGF-I estimula de forma direta ou indireta o recrutamento e ativação de osteoclastos. Os autores investigaram também os efeitos da IGF-I em culturas de células hematopoiéticas. A IGF-I apoiou fatores 
para a diferenciação osteoclastica. Estes dados indicaram que a IGF-I estimulou a reabsorção óssea osteoclástica através da ação direta ou indireta na geração e ativação osteoclastica.

Chen et al. (1993) examinaram a modulação da quantidade de IGFBPs por vários fatores de crescimento em culturas osteoblásticas de calvária. Os resultados mostraram que a expressão de IGFBP-4 foi aumentada pela bFGF e PDGF-BB e também pela TGF- $\alpha$ mas em menor quantidade. Por outro, lado o TGF- $\beta 1$ (fator de crescimento transformante $\beta 1$ ) diminuiu sensivelmente a expressão de IGFBP-4 e IGFBP-2. Já o PTH não interferiu na expressão das IGFBPs. Com esses dados os sutores concluíram que as células osteoblásticas são reguladas pela ação de vários fatores de crescimento.

Panagakos (1993) conclui em culturas osteoblásticas que houve a migração de osteoblastos e a proliferação celular em várias concentrações de IGF-I e II. Esse estudo indicou que as IGF-I e II estimulou a migração de células primárias de osteoblastos de rato in vitro. Estes resultados sugerem que as IGFs podem ter um importante papel no reparo ósseo após o trauma.

Canalis e Gabbitas (1994) estudaram os efeitos da BMP 2 sobre a transcrição e os níveis de IGF-I e II em culturas de células Ob de ratos. Os resultados obtidos sugerem que a BMP 2 aumenta a transcrição e os níveis de ambas IGF-I e II. Também houve um aumento nos níveis de RNA-m de IGF-I e II.

Gabbitas, Pash e Canalis (1994) realizaram estudo com objetivo de examinar os efeitos das TGF- $\beta 1$, bFGF, e PDGF-BB na transcrição e nos níveis de IGF-II células Ob de osso parietal de fetos de ratos. Os resultados deste estudo 
demonstraram que bFGF, TGFB1 e a PDGF-BB inibiram a transcrição esquelética celular de IGF-II, e que a TGF- $\beta 1$ e a PDGF-BB diminuíram os níveis do polipeptídio de IGF-II.

Hill, Reynolds e Meikle (1995) examinaram a ação da IGF-I e II na reabsorção óssea em culturas de calvária de ratos neonatais. Ambas as IGFs estimularam a reabsorção óssea através do receptor tipo I. Assim, a produção local de IGF-I e II pode modular interações entre osteoblastos e osteoclastos.

Goad et al. (1996) utilizaram células osteoblásticas humanas derivadas de osteossarcoma para determinar as ações da IGF-I sobre a trancrição do RNAm de VGEF (fator de crescimento vascular endotelial). Como resultado, a IGF-I aumentou abundantemente a transcrição de VGEF nas células osteoblásticas humanas derivadas de osteosarcoma de maneira dose dependente. Os autores concluíram que a IGF-I aumenta a síntese osteblástica de VGEF, o qual pode atuar localmente estimulando a angiogênese, um componente essencial da reparação, crescimento e remodelação ósseo.

Leung et al. (1996) investigaram se a IGF-I e a insulina estão envolvidas na regulação local de receptores de $\mathrm{GH}$ em osteoblastos. Os resultados permitiram aos autores concluírem que a IGF-I atua via receptores específicos na estimulação da proliferação celular e regulam negativamente os receptores de $\mathrm{GH}$. Assim, estes dados sugerem que existe um feedback negativo através da IGF-I que limita a resposta local dos tecidos alvos do $\mathrm{GH}$.

Steinbrech et al. (2000) examinaram a expressão in vitro de IGF-I e II em culturas de osteoblastos de calvária de rato mantidas em hipóxia ou normóxia. A 
hipóxia teve um pequeno impacto na expressão de RNA-m de IGF-I nas culturas de osteoblastos de calvária de rato e não houve mudanças substanciais na expressão de RNA-m de IGF-I sob as condições de hipóxia comparado com a normóxia. A hipóxia induziu um elevado nível de RNA-m de IGF-II nas culturas de osteoblastos de calvária de rato. Em contraste com a expressão de IGF-I a hipóxia resultou um aumento da expressão de RNA-m de IGF-II, tendo o pico em 48hs.

\subsection{O PAPEL DAS IGFS NO REPARO E CRESCIMENTO EM ÓSSOS LONGOS}

Karachaliou et al. (1996), estudando o reparo de ossos longos, objetivaram determinar se durante o processo de reparo ósseo havia qualquer mudança significativa nos níveis séricos de IGF-I. Para isso, os autores utilizaram um grupo de estudo constituído de 12 crianças (6 meninos e 6 meninas) com fraturas de ossos longos não complicadas. Todos os casos foram tratados com redução fechada sem qualquer complicação. Amostras de sangue foram obtidas de crianças depois de um período de 15-20 dias de pós-operatório. Um grupo de 24 crianças foi utilizado para controle. Os resultados obtidos permitiram concluir que houve um aumento dos níveis séricos de IGF-I em crianças com fraturas ósseas, sugerindo uma possível interação entre a IGF-I e o processo de reparo ósseo como outros experimentos têm sugerido em base de experimento em animais. 
Liu et al. (1999) estudaram a sinalização molecular no reparo de fraturas e na distração osteogênica concluindo que as IGFs não estão somente envolvidas na diferenciação e proliferação osteoblástica e condroblástica contribuindo para formação óssea, mas também modula a atividade osteoclástica participando da reparação óssea.

Schmidmaier et al. (2001) estudaram os efeitos da aplicação local de IGF-I e TGF- $\beta 1$ através de camada de Poly ( $D, L$ lactide) biodegradavel em fios de Kirscher na fixação de tíbias e fíbulas de ratos. Os resultados obtidos deixam claro que implantes cobertos com Poly (D, L lactide) + IGF-I e TGF- $\beta 1$ aceleram significativamente o reparo das fraturas. Por fim, não houve efeitos sistêmicos causados pelos fatores de crescimento.

Blumenfeld et al. (2002) testaram o envolvimento de TGF- $\beta$, IGF-I e uma combinação de TGF- $\beta$ e IGF-I na remodelação e regeneração em defeitos ósseos em tíbias de ratos idosos e seus efeitos na força mecânica, tipo e taxa do processo de reparo ósseo. A TGF- $\beta$ e a IGF-I induziram um aumento na taxa do processo de reparo ósseo e a qualidade biomecânica do novo osso. Os autores concluem que no futuro novas terapêuticas com fatores de crescimento poderão induzir a um aumento da massa óssea, na osteoindução nas cirurgias reconstrutivas em pacientes idosos.

Raschke et al. (2002) avaliaram a reparação de tíbias de mini-porco fraturadas cirurgicamente e reduzidas através de implantes (fio de Kirscher) divididos em 3 grupos: 1. implantes sem cobertura, 2. implantes com cobertura de polylactide e 3. implantes com cobertura de polylactide enriquecidos com IGF-I e 
TGF- $\beta 1$. Os resultados radiográficos mostraram que no grupo 3 houve completa formação de ponte óssea em 6 dos 8 animais, seguido do grupo 2 e com piores resultados os ratos tratados com implantes sem cobertura. Com relação ao volume do calo ósseo, o grupo 3 apresentou um volume ósseo significativamente maior em comparação com os grupos 2 e 1 . Ao teste mecânico, os melhores resultados foram do grupo 3. Diante disso os autores concluíram que o PDLLA (polylactide) incorporado de IGF-I e TGF- $\beta 1$ acelerou significativamente o reparo do gap ósseo e a remodelação do calo.

Schmidmaier et al. (2002) estudaram a melhora do reparo de fraturas de tíbia de ratos. A fratura foi reduzida com fios de Kischner (implante) cobertos e não cobertos com PDLLA (polylactide) acrescidos com IGF-I e/ou TGF- $\beta 1$ e houve administração sistêmica de $\mathrm{GH}$. A análise radiográfica mostrou que depois de 28 dias o gap das fraturas dos grupos tratados com implante coberto com PDLLA + IGF-I + TGF- $\beta 1$ + administração sistêmica de placebo e implante coberto com PDLLA + IGF-I + TGF- $\beta 1$ + administração sistêmica de GH apresentaram a formação completa óssea na fratura. Os testes mecânicos revelaram os melhores valores no grupo tratados com implante coberto com PDLLA + IGF-I + TGF- $\beta 1$ + administração sistêmica de placebo. Os autores concluíram que a aplicação local de IGF-I e TGF- $\beta 1$ e o uso sistêmico de GH mostraram efeitos estimulatórios no reparo de fraturas, entretanto não houve efeito estimulatório da combinação de ambos os métodos. 


\subsection{O PAPEL DAS IGFS NO REPARO E CRESCIMENTO EM OSSOS DE ORIGEM INTRA-MEMBRANOSA}

Schimid et al. (1989) extraíram o RNAm de ossos parietais de ratos normais e hipofisectomizados analisando a abundância do RNAm para procolágeno tipo I. Para isso os autores utilizaram ratos machos hipofisectomizados que foram tratados com IGF-I humana através de bomba osmótica e ratos normais para o grupo controle. Os autores concluíram que a IGF-I estimulou os níveis de RNA-m para colágeno ósseo em ratos hipofisectomizados.

Becker et al. (1992) compararam a formação óssea ao redor de implantes que foram cobertos com membranas de polytetrafluoroethyleno (PTFE) em combinação com osso liofilizado desmineralizado ou em combinação com PDGF e IGF-I. Para isto, os autores utilizaram 4 cachorros, num total de 24 implantes. Os autores concluíram que tanto os implantes cobertos apenas com polytetrafluoroethyleno (PTFE), quanto os cobertos polytetrafluoroethyleno (PTFE) mais PDGF e IGF-I foram igualmente efetivos na formação óssea ao redor de implantes. Assim, este método é efetivo na melhora da ossificação ao redor de implantes.

Thaller, Dart e Tesluk (1993) estudaram os efeitos da IGF-I em defeitos de tamanho crítico em calvária de ratos. Para isso utilizaram uma bomba de infusão em região subcutânea para administração de IGF-I e solução salina. Os resultados mostraram que no grupo controle (administração de solução salina) depois de 8 semanas a dimensão do defeito ósseo permaneceu inalterada. Já no grupo 
tratado com IGF-I depois de 8 semanas o defeito ósseo estava quase totalmente reparado, com osso semelhante ao do redor. Os autores concluíram que a IGF-I pode ter aplicações clínicas na potencialização do reparo ósseo intramembranoso. Dosagens ótimas e vias de administração necessitam de mais investigações, mas neste estudo, parece que a IGF-I tem potencial de acelerar o reparo de osso intramembranoso.

Thaller et al. (1993) estudaram os efeitos da IGF-I na reparação de fraturas do terço médio da face. Para isso utilizaram ratos Sprague-Dawley nos quais realizaram defeitos em arco zigomático. No grupo tratado com IGF-I, utilizaram uma bomba de infusão na região subcutânea. Baseados nos resultados, os autores concluíram que o grupo tratado com IGF-I de 4 semanas e o grupo controle de 8 semanas exibiram características semelhantes de reparo. Assim, a IGF-I parece ter potencial de reconstrução óssea nos defeitos do terço médio da face.

Pacientes com diabetes têm demonstrado significativo retardo do processo de reparo secundariamente à doença vascular de periferia, resultando na incidência de infecção. Assim, Thaller et al. (1995) avaliaram os efeito da IGF-I em defeitos ósseos críticos em ratos diabéticos, nos quais através de um acesso apropriado foi produzido um defeito ósseo de tamanho crítico, com $8 \mathrm{~mm}$ de diâmetro, em calvária. Em 15 animais foi realizada uma bolsa subcutânea para utilização de uma bomba de infusão onde receberam IGF-I. Os resultados mostraram que em 8 semanas no grupo controle o calo fibroso estava presente. Já no grupo tratado com IGF-I um novo osso havia se formado. Os autores concluíram que a IGF-I tem uma série de propriedades similares à insulina e pode 
acelerar a reconstituição de defeitos ósseos de tamanho crítico. Além disso, um efeito secundário sistêmico é a diminuição da glicemia sangüínea, podendo ser um benefício adicional no diabético.

Toung et al. (1998) estudaram o reparo de defeitos de osso nasal usando gel colágeno acrescido de IGF-I em ratos machos Sprague Dawley. Após 30 dias os animais foram examinados e os resultados obtidos demonstraram aumento significativo da ossificação nos grupos tratados com IGF-I.

Steinbrech et al. (1999) estudaram a expressão gênica de IGF-I e IGF-II no reparo de osteotomia em óssos intramembranosos. Para isso, realizaram osteotomias entre o segundo e terceiro molar, com aplicação de fixação externa. Os resultados mostraram que a expressão de RNAm para IGF-I decresceu agudamente depois da osteotomia, no pós-operatório de 3 dias; a expressão de RNAm para IGF-I cresceu até 2,8 vezes no PO de 5 dias; a expressão de RNAm para IGF-I chegou ao pico de 3,6 vezes no 7 dia de pós-operatório em relação ao controle; no pós-operatório de 9 dias, a expressão de RNAm de IGF-I decresceu para 2,3 vezes. Em contraste, a expressão de RNAm de IGF-II permaneceu inalterada nos pós-operatório de 3 e 5 dias. Esta expressão chegou ao pico no pós-operatório de 7 e 9 dias com, respectivamente, 2,3 vezes e 2,2 vezes. Concluindo, estes achados estão de acordo com os trabalhos que utilizam ossos longos. A análise temporal da expressão de IGF-I e IGF-II durante o reparo membranoso tem implicações clínicas devido à elucidação deste mecanismo regulatório que pode implicar novas terapias para acelerar e aumentar o reparo nestes pacientes. 
Stefani et al. (2000) avaliaram a associação de implantes dentários imediatos com PDGF/IGF-I em 3 períodos de tempo através de análises histológicas. Para isto o autor utilizou oito cachorros. Foram extraídos os $2^{\circ}, 3^{\circ} \mathrm{e}$ $4^{\circ}$ pré- molares, sendo que no lado experimental os alvéolos foram tratados com gel de metil-celulose com a associação de PDGF/IGF-I e após foram colocados os implantes. Já no lado controle, os alvéolos foram tratados apenas com gel de metil-celulose antes da instalação dos implantes. Os resultados estatísticos não revelaram diferenças estatísticas entre os grupos experimentais e o controle, apesar de que houve uma melhora na neoformação óssea do grupo experimental.

Nociti et al. (2000) avaliaram regeneração óssea ao redor de implantes imediatos parcialmente em contato com osso, com ou sem aplicação de PDGF e IGF-I. Os pré-molares mandibulares de cães foram removidos e o preparo para implante foi realizado. Vinte implantes foram colocados em 6 cachorros. Antes de cada inserção de um implante foram aplicadas PDGF e IGF-I num gel de metilcelulose ou somente o gel de metil-celulose como controle. Assim, este trabalho concluiu que a utilização da combinação de PDGF + IGF-I em gel de metilcelulose é uma alternativa para incrementar a ossificação ao redor de implantes com contato parcial com tecido ósseo.

Deep, Stemberger e Hillemanns (2003) estudaram a combinação de membranas de titânio cobertas com polylactide, IGF-I e TGF- $\beta 1$ na regeneração de defeitos ósseos de tamanho crítico em mandíbulas de ratos. Os resultados mostraram que no grupo tratado com a membrana de titânio coberta com polylactide, IGF-I e TGF- $\beta 1$ houve um completo reparo destes defeitos. Estes 
resultados apoiam a hipótese que membranas de titânio cobertas com polylactide, IGF-I e TGF- $\beta 1$ conseguem reparar defeitos ósseos de tamanho critico. 


\section{PROPOSIÇÃO}

O objetivo desta dissertação é, através do levantamento de literatura, avaliar e discutir, o papel atual das IGFs na reparação óssea, visando desenvolvimento futuro de trabalhos nesta área. 


\section{MATERIAL E MÉTODOS}

A pesquisa literária foi organizada utilizando os seguintes termos: insulinlike growth factor (IGFs) e bone repair. Esta pesquisa foi direcionada para trabalhos realizados entre os anos de 1957 e 2003.

Assim 72 referências foram analisadas selecionando os conteúdos de relevância para esta revisão de literatura. 


\section{DISCUSSÃO}

A descoberta da Insulina Semelhante a Fator de Crescimento ocorreu através de pesquisas iniciadas por Salmon e Daughaday (1957) que levou os autores a postularem que $\mathrm{o} \mathrm{GH}$ não estimulava sozinho $\mathrm{o}$ processo de crescimento in vitro ou in vivo de culturas de cartilagem, mas dependia de outros fatores. Estes fatores foram chamados primeiramente de sulfactantes e depois de somatomedinas. Mais tarde, Froesch et al. (1963) observaram que o soro exercia efeitos semelhantes à insulina nos tecidos alvo como músculos e tecidos adiposos. Já Pierson e Temin (1972) concluíram que moléculas encontradas no soro, quando adicionadas em meios de culturas, estimulavam a replicação celular. Neste mesmo ano Daughaday et al. (1972) afirmaram que "não há mais dúvidas sobre a importância destas moléculas no crescimento e resposta anabólica de tecidos esqueléticos e não esqueléticos". Dulak e Temin (1973) relataram que estas moléculas foram encontradas nas secreções de culturas de células hepáticas. Esta foi a primeira demonstração que as IGFs eram produzidas no fígado e que poderiam ter ação autócrina.

Rinderknecht e Humbel (1978) purificaram e caracterizaram as moléculas responsáveis por esta atividade semelhante à insulina. As IGFs não eram só funcionalmente mas também estruturalmente semelhantes à insulina. 
A partir deste ano (1978), no qual houve a caracterização das IGFs iniciaram-se pesquisas com objetivo de elucidar as suas funções, os locais de produção e os mecanismos de ação.

As IGFs não existem em sua forma livre no soro ou em outros fluídos corpóreos (ZAPF; WALDVOGEL; FROESCH, 1975; FROESCH et al., 1985; ZAPF et al., 1986), devido à sua rápida degradação, mas sim ligadas a proteínas chamadas IGFBPs (SCHLIEPHAKE, 2002; SCHWANDER et al., 1983). Dentre elas, seis proteínas ligantes (IGFBPs) das IGFs foram identificadas. Estas proteínas protegem as IGFs da degradação, facilitam o transporte das IGFs e regulam sua função celular. De todas as IGFBPs, a IGFBP5 é a mais abundante dentro da matriz óssea e existe uma hipótese que a função da IGFBP 3 e 5 é incorporar as IGFs dentro da matriz óssea mineralizada (LINKHART; MOHAN; BAYLINK, 1996; SCHLIEPHAKE, 2002). Por outro lado, Zapf et al. (1986) concluíram que apenas as IGFs e não as IGFs ligadas as IGFBPs são ativas nos tecidos alvo. Esta é a razão pela qual as IGFs podem estar em altas concentrações no soro sem causar hipoglicemia em sinergismo com a insulina ou outros efeitos adversos.

Com relação às ações das IGFs, Schliephake (2002) cita que são mediadas por proteínas ligantes as IGFBPs, por hormônios como exemplo o GH (Holly e Wass 1989; Murphy et al. 1987), e fatores como a nutrição (HERINGTON; KUFFER, 1981; FROESCH et I., 1985) e receptores das células alvo (RECHLER; NILLLEY 1985) que podem ser homólogos aos receptores de insulina segundo Butler e LeRoith (2001). 
Schwander et al. (1983) em seu trabalho citam que o fígado é o maior produtor de IGFs. Além do fígado, as IGFs podem ser produzidas por células de outros tecidos, como tecido ósseo em menor quantidade (Mayer; Schalch, 1983) descobriram que as IGFs poderiam ser produzidas por células de outros tecidos (como tecido ósseo) em menor quantidade, justificando inicialmente segundo Holly e Wass (1989) a possível ação local como fator de crescimento. Estas ações são comprovadas por trabalhos de Bautista, Mohan e Baylink (1990) que encontraram IGFs em abundância no tecido esquelético e trabalhos de Linkhart, Mohan e Baylink (1996) que observaram que as IGFs estão relacionadas a proliferação celular óssea e funções variadas, como a expressão do colágeno tipo 1. Por fim Schliephake (2002) cita que as IGFs têm ação quimiotática em osteoblastos de maneira dose dependente.

Bianda et al. (1997) concluíram que a IGF-I estimula rapidamente a remodelação óssea. Este trabalho está em concordância com MacCarthy, Changua e Centrella (2000).

\subsection{PAPEL DAS IGFS NO CRESCIMENTO ESQUELÉTICO}

Segundo Schoenle et al. (1982), a IGF-I administrada em ratos hipofisectomizados, medía os efeitos do GH sobre o crescimento de ossos longitudinais e ganho de peso. Este trabalho está em acordo com trabalhos 
realizados por Isagaard et al. (1986) e Mathews et al. (1988). Estes trabalhos comprovam a interação direta entre o GH e a IGF-I.

DeChiara, Efstrstiadis e Robertson (1990) comprovaram a relação entre a expressão de IGF-II e o crescimento esquelético de ratos. Já Powell-Braxton et al. (1993) sugerem a hipótese de que a IGF-II funciona predominantemente no crescimento fetal enquanto a IGF-I no pós-natal (Bikle et al., 1994). Estes dados estão de acordo com Liu et al. (1993) que observaram que ratos com deficiência de IGF-I morreram ao nascimento por falência respiratória, e de acordo com Baker et al. (1993) que observaram que ratos mutantes para IGF-I nulos sobrevivem chegando a $30 \%$ do peso dos ratos normais.

Assim, a revisão de literatura mostrou que em animais as IGFs são de fundamental importância no crescimento esquelético, tanto em nível pré-natal com a IGF-II, como em nível pós-natal com a IGF-I.

\subsection{PAPEL DAS IGFS EM CULTURAS ÓSSEAS}

Parte das ações das IGFs nos tecidos ósseos foram elucidadas através de experimentos em culturas ósseas. Assim, trabalhos têm demonstrado que a IGF-I estimula a síntese de DNA e colágeno, indicando que a IGF-I é importante na regulação do crescimento aposicional (CANALIS, 1980; CANALIS, MACCARTHY; CENTRELLA, 1988; PFEILSCHIFTER, 1990). 
O crescimento ósseo estimulado pela IGF-I parece ser conseqüência de pelo menos 2 sinais regulatórios; o primeiro, é um efeito na diferenciação de osteoblastos aumentando a produção de colágeno ósseo, que também tem participação da IGF-II, (HOCK; CENTRELLA; CANALIS, 1988; MACCARTHY; CENTRELLA; CANALIS, 1989), enquanto o segundo, é um aumento na replicação de células osteoprogenitoras, resultando em um grande número de osteoblastos funcionais. Embora esses 2 sinais trabalhem juntos no aumento da produção óssea, Hock, Centrella e Canalis (1988) afirmam que eles são bioquimicamente dissociados. Isto pode ser interessante nas futuras terapias com as IGFs, pois trabalhando em cada sinal regularatório em momentos distintos poderão melhorar a eficiência da reparação óssea.

O efeito na síntese de colágeno ósseo e DNA ocorre através dos receptores de IGF-I (CENTRELLA; MACCARTTHY; CANALIS, 1990; CANALIS; MCCARTHY; CENTRELA, 1991). Por outro lado Hock, Centrella e Canalis (1988) afirmam que a IGF-I não é o único fator de crescimento responsável pela formação óssea. Assim os autores concluem que a IGF-I não é o único fator de crescimento que aumenta a transcrição de DNA.

A expressão das IGFs pelo tecido ósseo é regulada por diversas substâncias, que de maneira direta ou indireta pode influenciar no processo de reparo ósseo. Dentre estas substâncias o PTH (LINKHART; MOHAN, 1989; CANALIS et al., 1989), TGF-ß1(ELFORD; LAMBERTS, 1990; LINKHART; KEFFER, 1991) e a BMP 2 (CANALIS; GABBITAS, 1994) estimulam a liberação de IGF-I e IGF-II. Assim, estas substâncias podem influenciar através das IGFs, o processo de reparo ósseo. 
Também a PGE 2 (MACCARTHY et al., 1991), o GH (LEUNG et al., 1996) são potentes estimuladores da produção de IGF-I, enquanto o estradiol pode estimular diretamente a produção de RNAm de IGF-I (ERNST; HEATH; RODAN, 1989). Já MacCarthy, Centrella e Canalis (1990) concluíram que o cortisol inibe a transcrição de IGF-I em células esqueléticas. Kurose et al. (1990) demonstraram a interação sobre os receptores celulares entre a IGF-I e 1,25- $(\mathrm{OH})_{2} \mathrm{D}_{3}$.

Tratando especificamente da IGF-II a 1,25-dihidroxivitamina $\mathrm{D}_{3}$ (LINKHART; KEFFER, 1991) e a BMP 2 (Canalis; Gabbitas, 1994) aumentaram a liberação de IGF-II em culturas ósseas. Já a cicloheximida, T3, sal sódio, TGF- $\beta 1$ e PDGF (CANALIS; CENTRELA; MCCARTHY, 1991) bem como o GH (MCCARTHY; CENTRELLA; CANALIS, 1992) não estimularam nem inibiram a produção esquelética da IGF-II. Os corticosteróide e a bFGF promoveram uma inibição na produção esquelética da IGF-II. Este estudo esta de acordo com Canalis; Centrela e Mccarthy (1991) e McCarthy, Centrella e Canalis (1992). Em contraste, Gabbitas, Pash e Canalis (1994) não encontraram os mesmos resultados, pois em seu estudo a TGF- $\beta 1$, bFGF e PDGF-BB inibiram a transcrição esquelética de IGF-II.

Falando especificamente da ação do $\mathrm{GH}$ sobre os tecidos ela ocorre através da IGF-I (LEUNG et al., 1996) já que a IGF-II parece não ser estimulada in vitro por este hormônio (MCCARTHY; CENTRELLA; CANALIS, 1992).

Steinbrech et al. (2000) demonstraram que a hipóxia induziu um elevado nível de RNA-m de IGF-II nas culturas osteoblásticas de calvária de rato em contraste com a expressão de IGF-I. Estes dados demonstram que este fator de 
crescimento é de fundamental importância na fase inicial do reparo ósseo onde o aporte sangüíneo é diminuto.

As IGF-I e II apresentam efeito quimiotático que podem estimular a migração primária de osteoblastos de rato in vitro. Estes resultados sugerem que as IGFs podem ter um importante papel no reparo ósseo após o trauma, já que promovem a migração osteoblástica para o sítio de reparo. Isto é de grande importância, pois durante o processo de reparo ósseo, o recrutamento de células para o sítio de reparo geralmente envolve a migração de osteoblastos provenientes de áreas adjacentes ao sítio de reparo. Acredita-se que esta migração é em resposta a agentes quimiotáticos presentes no meio (PANAGAKOS, 1993). Presume-se que a fonte desses agentes quimiotáticos sejam os fatores de crescimento incorporados durante o desenvolvimento da matriz extracelular por osteoblastos enquanto ocorre a síntese de osso (BAUTISTA; MOHAN; BAYLINK 1990). Além da migração osteoblástica, Goad et al (1996) observaram que a IGF-I aumentou abundantemente a transcrição de VGEF concluindo que a IGF-I aumenta a síntese osteblástica de VGEF, o qual pode atuar localmente estimulando a angiogênese, um componente essencial da reparação, crescimento e remodelação óssea.

Mochizuki et al. (1992), demonstrou que a IGF-I estimula a reabsorção óssea através da ação direta ou indireta na geração e ativação osteoclástica. Este trabalho deixa claro que as IGFs atuam também na fase de remodelação óssea. Hill, Reynolds e Meikle (1995) confirmam a ação sobre os osteoclástos acrescentando também que a IGF-II participa deste processo.

Por fim Chen et al. (1993) concluíram que a secreção IGFBP-4 foi extremamente incrementada pela bFGF e PDGF-BB e também pelo TGF- $\alpha$, mas 
em menor quantidade. Por outro lado, o TGF- $\beta 1$ diminuiu sensivelmente a secreção de IGFBP-4 e IGFBP-2. Já o PTH não interferiu na secreção das IGFBPs. Esses dados levam a conclusão que as células osteoblásticas são reguladas pela ação de vários fatores de crescimento. Esses fatores de crescimento podem modular autocrinamente ou paracrinamente as ações das IGFs via esses efeitos nas IGFBPs.

\subsection{O PAPEL DAS IGFS NO REPARO EM ÓSSOS LONGOS}

Karachaliou et al. (1996) concluíram que houve um aumento dos níveis séricos de IGF-I em crianças com fraturas de ossos longos, sugerindo uma possível interação entre a IGF-I e o processo de reparo ósseo, como outros experimentos têm sugerido em base de experimento em animais. Este trabalho está em acordo com trabalho de Liu et al. (1999) que confirmou a participação das IGFs na sinalização molecular no reparo de fraturas e na distração osteogênica, contribuindo para formação óssea e também modulando a atividade osteoclástica participando na reparação óssea.

Schmidmaier et al. (2001) observaram que fios de Kirscher recobertos de Poly ( $D$, L lactide) biodegradável acrescidos com IGF-I e TGF- $\beta 1$ para fixação de fraturas de ossos longos de ratos aceleram significativamente o reparo das fraturas. Estes dados estão de acordo com Raschke et al. (2002) e Schmidmaier et al. (2002). Estes autores também realizaram a administração sistêmica de GH, 
além dos fios de Kirshiner recobertos, também com bons resultados. Estes estudos demonstram novas perspectivas no reparo de fraturas, podendo diminuir consideralvelmente a morbidade dos pacientes.

Blumenfeld et al. (2002) observaram que a TGF- $\beta$ e a IGF-I em defeitos ósseos em tíbias de ratos idosos induziram um aumento na taxa do processo de reparo ósseo e a qualidade biomecânica do novo osso. No futuro, tratamentos poderão induzir um aumento na massa óssea e osteoindução em cirurgias reconstrutivas de idosos.

\subsection{O PAPEL DAS IGFS NO REPARO E CRESCIMENTO EM OSSOS DE ORIGEM INTRA-MEMBRANOSA}

Schimid et al. (1989) observaram que a IGF-I estimulou os níveis de RNA-m para colágeno ósseo em ratos hipofisectomizados. Este trabalho dá subsídios para trabalhos com reparos em ossos de origem intramembranosa.

Becker et al. (1992) utilizando cachorros, observaram que tanto os implantes cobertos apenas com polytetrafluoroethyleno (PTFE), quanto os cobertos polytetrafluoroethyleno (PTFE) mais PDGF e IGF-I foram igualmente efetivos na formação óssea em torno de implantes, concluindo que este método é efetivo na melhora da ossificação em torno dos implantes. Nesta mesma linha de pesquisa Stefani et al. (2000) obtiveram resultados diferentes, pois não observaram diferenças entre o grupo controle e o experimental no qual utilizaram 
implantes imediatos em associação com PDGF + IGF-I em gel de metil-celulose nos alvéolos dentários. Por outro lado, Nociti et al. (2000) concluíram que a utilização da combinação de PDGF + IGF-I em gel de metil-celulose é uma alternativa para incrementar a ossificação entorno de implantes com contato parcial com tecido ósseo.

Estudando defeitos ósseos de tamanho crítico em ratos, diversos estudos têm demonstrado que a aplicação de IGF-I, através de via subcutânea (THALLER; DART; TESLUK, 1993; THALLER et al., 1993; THALLER et al., 1995), gel colágeno acrescido de IGF-I utilizados por Toung et al. (1998), repararam os defeitos com bons resultados, podendo se tornar no futuro uma terapia viável no reparo ósseo em cirurgia buco-maxilo-facial.

Tratamentos cirúrgicos para defeitos ósseos de tamanho crítico através de membranas, tem sido parte integrante da odontologia. Mas este tipo de tratamento, em muitos casos, é limitada ou até ineficaz. Assim, Deep, Stemberger e Hillemanns (2003) estudaram a eficácia da combinação de membranas de titânio cobertas com polylactide, IGF-I e TGF- $\beta 1$ na regeneração de defeitos ósseos de tamanho crítico em mandíbulas de ratos, obtendo bons resultados.

Steinbrech et al. (1999), estudaram a expressão gênica de IGF-I e IGF-II no reparo de osteotomia em óssos intramembranosos. Os resultados demonstraram que tanto a IGF-I como a II chegaram ao pico de produção no 7 dia de pósoperatório. A análise temporal gênica de IGF-I e IGF-II durante o reparo membranoso tem implicações clínicas. Devido a elucidação deste mecanismo 
regulatório pode se desenvolver terapêuticas para acelerar e aumentar o reparo nestes paciente 


\section{CONCLUSÕES}

A partir dos autores estudados conclui-se:

- A IGF-I e IGF-II, em culturas, atuam na diferenciação de osteoblastos aumentando a síntese de colágeno ósseo, e na proliferação de células osteoprogenitoras. Por fim, a IGF-I também atua na síntese de DNA.

- As IGFs atuam na expressão de VGEF em culturas de osteoblastos e na expressão de novos capilares e também estimulam a reabsorção óssea osteoclástica participando claramente da fase de remodelação óssea.

- Os trabalhos com animais sugerem a hipótese de que a IGF-II funciona predominantemente no crescimento fetal enquanto a IGF-I no pós-natal, sendo um fator de comprovada ação no crescimento esquelético.

- Em culturas o PTH, TGF- $\beta 1, \mathrm{PGE}_{2}, \mathrm{BMP} 2, \mathrm{GH}$ e o estradiol, estimulam de alguma maneira o aumento dos níveis de IGF-I. Já os GH, T3 e o PTH tem ação comprovada no aumento dos níveis de IGF-II.

- Em experimentos com culturas de osteoblastos a hipóxia resultante de traumas ou danos cirúrgicos aumentou a expressão de IGF-II, o que não aconteceu com a IGF-I.

- Há um aumento sérico de IGF-I em crianças com fraturas ósseas.

- Terapêuticas com gel de colágeno (T1CG) acrescida com IGF-I e II em defeitos ósseos de tamanho crítico ou a combinação de PDGF + IGF-I com um de gel 
de metil-celulose entorno de implantes osteointegrados mostraram bons resultados na reparação óssea em animais.

- A literatura demonstrou que a utilização de Poly (D, L-lactide) revestindo fios de Kirschner, parafusos intrafagmentários, implantes, membranas de titâneo, entre outros, em associação com IGF-I e TGF- $\beta 1$ permitiu um completo reparo ósseo em animais.

- Nos estudos em animais as IGF-I e II chegaram ao pico de produção no 7 dia de pós-operatório em osteotomias de ossos com origem intramembranosa. 


\section{REFERÊNCIAS ${ }^{1}$}

Baker J, Liu J-P. Robertson EJ, Efstratiadis A. Role of insulin-like growth factors in embrionic and postnatal growth. Cell 1993;75(8):73-82.

Bautista CM, Mohan S, Baylink D. Insulin-like growth factor I and II are present in the skeletal tissues of ten vertebrates. Metabolism 1990; 39(1): 96-100.

Becker W, Lynch SE, Lekholm U, Becker BE, Caffesse R, Donath K et al. A comparison of ePTFE membranes alone or in combination with platelet-derived growth factors and insulin-like growh factor I or demineralized freeze-dried bone in promoting bone formation around immediate extraction socke implants. J Periodontol 1992; 63(11): 929-40.

Bianda T, Hussain MA, Glatz Y, Bouillon R, Froesch ER, Schmid C. Effects of short-term insulin-like growth factor I or growth hormone treatment on bone turnover, renal phosphate reabsorption and 1,25-Dihydroxyvitamin $D_{3}$ production in healthy man. J Int Med 1997; 241:143-50.

Bikle DD, Harris J, Halloran BP, Roberts CT, Leroith D, Morey-Holton E. Expression of the genes for insulin-like growth factors and their receptor in bone during skeletal growth. Am J Physiol Endocrinol Metab 1994;267(30): 278-86.

Blumenfeld I, Srouji S, Lanir Y, Laufer D, Livne E. Enhancement of bone defect healing in old rats by TGF- $\beta 1$ and IGF-I. Experimental Gerontology 2002; 37: 55365.

Butler AA, LeRoith D. Minireview: tissue-specific versus generalized gene targeting of igf1 and igf1r genes and their roles in insulin-like growth factor fisiology. Endocrinology 2001; 142(5):1685-8.

Canalis E. Effect of insulinlike growth factor I on DNA and protein synthesis in cultured rat calvaria. J Clin Invest 1980;66:709-19.

\footnotetext{
${ }^{1}$ De acordo com Estilo Vancouver. Abreveatura de periódicos segundo base de dados MEDLINE.
} 
Canalis E, Centrella M, Burch W, MacCarthy TL. Insulin-like growth factor I mediates selective anabolic effects of parathyroid hormone in bone cultures. J Clin Invest 1989;83:60-5.

Canalis E, Centrella M, MacCarthy TL. Regulation of insulin-like grwth factor II production in bone cultures. Endocrinology 1991;129(5):2457-62 .

Canalis E, Gabbitas B. Bone morphogenetic protein 2 increases insulin-like growth factor I and II transcripts and polypeptide levels in bone cell cultures. J Bone and Mineral Research 1994;9(12):1999-2005.

Canalis E, MacCarthy TL, Centrella M. Isolation and characterization of insulin-like growth factor I (Somatomedi-C) from cultures of fetal rat calvarie. Endocrinology 1988;122(1):22-7.

Canalis E, MacCarthy TL, Centrella M. Effects of desamino-(1-3)-insulin-like growth factor I on bone cell function in rat calvarial cultures. Endocrinology 1991;129(1):534-41.

Chen TL, Chang LY, DiGregorio DA, Perlman AJ, Huang Y. Growth factor modulation of insulin-like growth factor-binding proteins in rat osteoblastic-like cells. Endocrinology 1993;133(3):1382-9.

Centrella M, MacCartthy TL, Canalis E. Receptors for insulin-like growth factor I and II in osteoblast-enriched cultures from fetal rat bone. Endocrinology 1990; 126(1):39-44.

Daughaday WH, Hall K, Raben MS, Salmon WD Jr, Van den Brande JL, Van Wyk JJ. Somatomedin: proposed designation for sulphation factor. Nature 1972;235(14):107.

DeChiara TM, Efstratiadis A, Robertson EJ. A growth-deficiency phenotype in heterozygous mice carrying an insulin-like growth factor II gene disrupted by targeting. Nature 1990; 345(3):78-80. 
Deppe $H$, Stemberger A, Hillemanns M. Effects of osteopromotive and antiinfective membranes on bone regeneration: an experimental study in rat mandibular defects. Int J Oral Maxillofac Implants 2003;18(3):369-76.

Dulak N, Temin H. A partially purified polypeptid fraction from rat liver cell conditioned médium with multiplication stimulating activity for embryo fibroblasts. J Cell Physiol 1973; 81:153-160.

Elford PR, Lamberts SWJ. Contrasting modulation by transforming growth factor $\beta 1$ of insulin-like growth factor I production in osteoblastic and chondrocytes. Endocrinology 1990; 127(4):1635-1639.

Ernst M, Heath JK, Rodan GA. Estradiol effects on proliferation, messenger ribonucleic acid for collagen and insulin-like growth factor-I, and parathyroid hormone-stimulated adenylate cyclase activity in osteoblastic cells from calvariae and long bones. Endocrinology 1989;125(2):825-33.

Foresch ER, Bürgi H, Ramseier EB, Bally P, Labhart A. Antibody-suppressible and nonsuppressible insulin-like activities in human serum and their physiologic significance. An insulin assay with adipose tissue of increase precision and specificity. J Clin Invest 1963; 42(11):1816-34.

Froesch ER, Schmid C, Schwander J, Zapf J. Actions of insulin-like growth factors. Ann Rev Physiol 1985;47:443-67.

Gabbitas B, Pash J, Canalis E. Regulation of insulin-like growth factor II synthesis in bone cell cultures by skeletal growth factor. Endocrinology 1994; 135(1): 284289.

Goad DL, Rubin J, Wang H, Tashjian HÁ, Patterson C. Enhanced expression of vascular endotelial growth factor in human SaOS-2 osteoblast-like cells and murine osteoblasts induced by insulin-like growth factor I. Endocrinology 1996; 137(2):2262-68.

Herington AC, Kuffer AD. Identification of a specific inhibitor of nonsuppressible insulin-like activity in a partially purified human serum fraction. Endocrinology 1981;109(5):1634-40. 
Hill PA, Reynolds JJ, Meikle MC. Osteoblasts mediate insulin-like growth factor I and II stimulation of osteoclast formation and function. Endocrinology 1995; 136(1):124-31.

Hock JM, Centrella M, Canalis E. Insulin-like growth factor I has independent effects on bone matrix formation and cell replication. Endocrinology 1988; 122(1):254-60.

Holly JMP, Wass JAH. Insulin-like growth factors; autocrine, paracrine or endocrine? New perspectives of the somatomedin hypothesis in the light of recent developments. J Endocrinology 1989;122: 611-8.

Isgaard J, Nilsson A, Lindahl A, Jansson JO, Isaksson OGP. Effects of local administration of GH and IGF-I on longitudinal bone growth in rats. Am J Physiol Endocrinol Metab 1986; 250(13):367-72.

Karachaliou FH, Stamogiannou L, Maravelias K, Bartsocas CS, Koutselinis A. Long bone fracture healing: IGF-I concentrations and specific binding to erythrocytes. J Pead Endocrinol Metabol 1996; 9(4):491-95.

Kurose H, Yamaoka K, Okada S, Nakajima S, Seino Y. 1,25-Dihydroxyvitamin $D_{3}$ $\left[1,25-(\mathrm{OH})_{2} \mathrm{D}_{3}\right]$ increases insulin-like growth factor I (IGF-I) receptors in clonal osteoblastic cells. Study on interaction of IGF-I and $1,25-(\mathrm{OH})_{2} \mathrm{D}_{3}$. Endocrinology 1990; 126(4):2088-94.

Leung K, Rajkovic IA, Peters E, Markus I, Van Wyk JJ, Ho KKY. Insulin-like growth factor $I$ and insulin down-regulate growth hormone $(\mathrm{GH})$ receptors in rat osteoblasts: evidece for a peripheral feedack loop regulating $\mathrm{GH}$ action. Endocrinology 1996; 137(7): 2694-702.

Linkhart TA, Keffer MJ. Differential regulation of insulin-like growth factor I (IGF-I) and IGF-II release from cultured neonatal mouse calvaria by parathyroid hormone, transforming growth factor $\beta$, and 1,25-Dihydroxyvitamin $D_{3}$. Endocrinology 1991; 128(3):1511-8. 
Linkhart AT, Mohan S. Parathyroid hormone stimulates release of insulin-like growth factor I (IGF-I) and IGF-II from neonatal mouse calvaria in organ culture. Endocrinology 1989; 125(3):1484 - 91.

Linkhart TA, Mohan S, Baylink DJ. Growth factor for bone growth and repair: IGF, TGF $\beta$ and BMP. Bone 1996;19(1):1s-12s.

Liu JP, Baker J, Perkins S, Robertson EJ, Efstratiadis A. Mice carring null mutations o genes encoding insulin-like growth factor I (Igf-1) and type 1 IGF receptor (lgf1r). Cell 1993;75(8):59-72.

Liu Z, Luyten FP, Lammens J, Dequeker J. Molecular signaling in bone fracture healing and distraction osteogenesis. Histol-Histopathol 1999;14: 587-95.

Mathews LS, Hammer RE, Brinster RL, Palmiter RD. Expression of insulin-like growth factor-1 in transgenic mice with elevate levels o growth hormone is correlated with growth. Endocrinology 1988; 122(1): 433-437.

MacCarthy TL, Changhua JL, Centrella M. Links among growth factors, hormones and nuclear factors with essential roles in bone formation. Crit Rev Oral Biol Med 2000;11(4):409-22.

MacCarthy TL, Centrella M, Canalis E. Regulatory effects of insulin-like growth factor I and II on bone collagen synthesis in rat calvarian cultures. Endocrinology 1989; 124(1):301-9.

MacCarthy TL, Centrella M, Canalis E. Cortisol inhibits the synthesis of insulin-like growth factor I in skeletal cells. Endocrinology 1990; 126(3):1569-75.

MacCarthy TL, Centrella M, Canalis E. Constitutive synthesis of insulin-like growth factor II by primary osteoblast-enriched cultures from fetal rat calvarie. Endocrinology 1992;130(3):1303-8.

MacCarthy TL, Centrella M, Raisz LG, Canalis E. Prostaglandin $E_{2}$ stimulates insulin-fike growth factor I syntesis in osteoblast-enriched cultures from rat bone. Endocrinology 1991;128(6): 2895-900. 
Mayer PW, Schalch DS. Somatomedin synthesis by a subclone of buffalo rat liver cells: characterization and evidence for immediate secretion of de novo synthesized hormone. Endocrinology 1983;113:588-95.

Mochizuki H, Hakeda Y, Wakatsuki N, Usui N, Akashi S, Sato T, et al. Insulin-like growth factor I supports formation and activation of osteoclasts. Endocrinology 1992;131(3):1075-80.

Murphy LJ, Bell GL, Duckworth ML, Friesen HG. Indentification, characterization, and regulation of a rat complementary deoxyribonucleic acid which encodes insulin-like growth farctor-I. Endocrinology 1987;121(2):684-91.

Nociti FH Jr, Stefani CM, Machado MAN, Sallum EA, Toledo S, Sallum AW. histometric evaluation of bone regeneration around immediate implants Partially in contact with bone: a pilot study in dogs. Implat Dent 2000;9(4):321-25.

Panagakos FS. Insuli-like growth factor I and II stimulate chemiotaxis os osteoblasts isolated from fetal rat calvaria. Biochimie 1993; 75:991-4.

Pfeilschifter J, Oechsner M, Naumann A, Gronwald RGK, Minne HW, Ziegler R. Stimulation of bone matrix apposition in vitro by local growth factors: A comparison between insulin-like growth factor I, platelet-derived growth factor, and transforming growth factor $\beta$. Endocrinology 1990;127(1):69-75.

Pierson RW, Temin HM. The partial purification from calf serum of fraction with multiplicaiton stimulating activity for chicken fibroblats in the cell culture and with non-supressible insulin like activity. J Cell Physiol 1972; 79:319-30.

Powel-Braxton L, Hollingshad P, Warburton C, Dowd M, Pitts-Meek S, Dalton D, et al. IGF-I is required for normal embryonic growth in mice. Genes Dev 1993; 7:2609-17.

Raschke M, Wildemann B, Inden P, Bail H, Flyvbjerg A, Hoffmann J, et al Insulinlike growth factor-1 and transforming growth factor- $\beta 1$ accelerates osteotomy healing using polylactide-coated implants as a delivery system: A biomechanical and histological study in minipigs. Bone 2002;30(1):144-51. 
Rechler MM, Nillley SP. The nature and regulation of the receptors for insuli-like growth factors. Ann Rev Physiol 1985;47:425-42.

Rinderknecht E, Humbel RE. The amino acid sequence of human IGF-I and its structural homology with proinsulin. J Biol Chem 1978; 253: 2769-76.

Salmon WD, Daughaday WH. A horrnally controlled serum factor which stimulates sulfate incorporation by cartilage in vitro. J Lab Clin Med 1957; 49: 825-36.

Schliephake $\mathrm{H}$. Bone growth factors in maxilofacial skeletal reconstruction. Int $\mathrm{J}$ Oral Maxillofac Surg 2002; 31: 469-84.

Schimid C. Insulin-like growth factors. Cell Biol Int 1995; 19(5): 445-57.

Schmid C, Guler HP Rowe D, Froesch R. Insulin-Like growth factor I regulates types I procollagen messenger ribonucleic acid steady state levels in bone of rats. Endocrinology 1989;125(3):1575-80.

Schmidmaier G, Wildemann B, Bail H, Lucke M, Fuchs T, Stemberger A, et al. Local application of growth factors (IGF-I and TGF- $\beta 1$ ) from a biodegradable Poly $(\mathrm{D}, \mathrm{L}$-lactide $)$ coating of osteosynthetic implants accelerates fracture healling in rats. 2001; Bone 28(4):341-50.

Schmidmaier G, Wildemann B, Heeger J, Gãbelein T, Flyvbjerg A, Bail HJ, et al. Improvement of fracture healing by systemic administration of growth factor-1 and transforming growth factor- $\beta 1$. Bone 2002; 31(1):165-72.

Schoenle E, Zapf J, Humbel RE, Froesch ER. Insulin-like growth factor I stimulates growth in hipophyectomized rats. Nature 1982; 296(18):252-3.

Schwander JC, Hauri C, Zapf J, Froech ER. Synthesis and secretion of insulin-like growth factor and its binding protein by the perfused rat liver: dependence on growth hormone status. Endocrinology 1983;113(1):297-305.

Stefani CM, Machado MAN, Sallum EA, Sallum WA, Toledo S, Nociti FH Jr. Platelet-derived growth factor/insulin-like growth factor I combination and bone regeneration around implants placed into extraction sockets: a histometric study in dogs. Implant Dent 2000; 9:126-30. 
Steinbrech DS, Mehrara BJ, Rowe NM, Dudziak ME, Saadeh PB, Gittes GK, et al. Gene expression of Insulin-like growth factor I and II in rat mambranous osteotomy healling. Ann Plast Surg 1999;42:481-7.

Steinbrech DS, Mehrara BJ, Saadeh PB, Greenwald JÁ, Spector JÁ, Gittes GK, et al. Hipoxia increases insulin-like growth factor gene expression in rat osteoblasts. Ann Plast Surg 2000;44(5):529-35.

Thaller SR, Dart A, Tesluk $\mathrm{H}$. The effects of insulin-like growth factor-I on criticalsize calvarial defects in sprague-dawley rats. Ann Plast Surg 1993;31: 429-33.

Thaller SR, Hoyt J, Tesluk H, Holmes R. Effect of insulin-like growth factor-I on zygomatic arch bone regeneration: a preliminary histological and histometric study. Ann Plast Surg 1993;31:421-8.

Thaller SR, Lee TJ, Armstrong M, Tesluk H, Stern JS. Effect of insulin-like growth factor type I on critical-size defects in diabetic rats. J Craniofac Surg 1995;6(3):218-23.

Toung JS, Griffin A, Ogle RC, Lindsey WH. Repair of nasal defects using collagen gels containing insulin-like growth factor-I. Laryngoscope 1998; 108(11, Pt 1): 1654-8.

Zapf J, Waldvogel M, Froesch ER. Binding of non-suppressible insulin like human activity to human serum: evidence for a carrier protein. Arch Biochem Biophys 1975;168:345-68.

Zapf J, Hauri C, Waldvogel M, Froesch ER. Acute metabolic effects and half-lives of half-lives of intravenously administered insulinlike growth factors I and II in normal and hypophysectomized rats. J Clin Invest 1986;77:1768-75. 